\title{
Synthesis of wavelength-tunable luminescent gold and gold/silver nanodots $\dagger$
}

\author{
Chih-Ching Huang, ${ }^{b}$ Hao-Ying Liao, ${ }^{a}$ Yen-Chun Shiang, ${ }^{a}$ Zong-Hong Lin, ${ }^{a}$ Zusing Yang ${ }^{a}$ \\ and Huan-Tsung Chang $* a$
}

\author{
Received 21st May 2008, Accepted 13th November 2008 \\ First published as an Advance Article on the web 16th December 2008 \\ DOI: $10.1039 / b 808594 c$
}

This paper describes the preparation of wavelength-tunable luminescent Au nanodots (NDs) and Au/ Ag NDs at room temperature. Controlling the molar ratios of tetrakis(hydroxymethyl)phosphonium chloride (THPC) to $\mathrm{Au}$ ions and of $\mathrm{Ag}$ ions to $\mathrm{Au}$ ions allows the preparation of different sizes of $\mathrm{Au}$ and $\mathrm{Au} / \mathrm{Ag}$ nanoparticles. We then used 11-mercaptoundecanoic acid (11-MUA) to react with the as-prepared nanoparticles to prepare wavelength-tunable luminescent 11-MUA-Au NDs and 11-MUA-Au/Ag NDs, respectively. Our prepared luminescent NDs exhibit a number of attractive optical properties: tunable luminescence wavelengths $(456-640 \mathrm{~nm})$, long lifetimes $(>250 \mathrm{~ns})$, and large Stokes shifts $(>100 \mathrm{~nm})$. These properties suggest that the as-prepared 11-MUA-Au NDs and 11-MUA-Au/Ag NDs would be suitable for use in sensing applications after bio-conjugation.

\section{Introduction}

Gold nanoparticles (Au NPs) exhibit size-dependent surface plasmon resonance (SPR) absorption properties when their conducting electrons in both the ground and excited states are confined to dimensions smaller than the electron mean free path (ca. $20 \mathrm{~nm}) .{ }^{1-3}$ Unlike Au NPs having sizes greater than $4 \mathrm{~nm}$, spherical gold nanodots (Au NDs) smaller than $2 \mathrm{~nm}$ that are protected by a monolayer of an alkanethiol or polymer exhibit luminescence properties as a consequence of quantum confinement effects. ${ }^{4-12}$ Alkanethiol-bound Au NDs (RS-Au NDs) exhibit luminescence in the spectral region from the visible to the near-IR when excited in the UV region; ${ }^{4-11}$ their emission quantum yields (QYs) are small (ca. 0.001-5\%). ${ }^{4-9}$ In contrast, $\mathrm{Au}$ NDs (diameter: $<1 \mathrm{~nm}$ ) protected by polyamidoamine (PAMAM) dendrimers or polyethylenimine (PEI) exhibit more stable and stronger (QY: >10\%) luminescence properties relative to RS-Au NDs. ${ }^{13,14}$

Previously, we reported the preparation of RS-Au NDs of various sizes that fluoresced at wavelengths within the range 501$613 \mathrm{~nm}$, with QYs ranging from 0.0062 to $3.1 \%{ }^{15} \mathrm{We}$ controlled the luminescence wavelength of these RS-Au NDs by varying the size of the alkanethiol. In this present investigation, we extended our study to the preparation of $\mathrm{Au}$ and $\mathrm{Au} / \mathrm{Ag}$ NDs whose luminescence could be controlled by varying the molar ratios of tetrakis(hydroxymethyl)phosphonium chloride (THPC) to $\mathrm{Au}$ ions (for the $\mathrm{Au}$ NDs) and of $\mathrm{Ag}$ ions to $\mathrm{Au}$ ions (for the $\mathrm{Au} / \mathrm{Ag}$ alloy NDs). First, we prepared a Au NP solution through reduction of $\mathrm{HAuCl}_{4} \cdot 3 \mathrm{H}_{2} \mathrm{O}$ with THPC, which acted as both a reducing and capping agent. ${ }^{16}$ Through variation of the initial mole ratio of THPC to hydrogen tetrachloroaurate(III)

${ }^{a}$ Department of Chemistry, National Taiwan University, 1, Section 4, Roosevelt Road, Taipei, 106, Taiwan.E-mail: changht@ntu.edu.tw; Fax: +011-886-2-33661171; Tel: +011-886-2-33661171

${ }^{b}$ Institute of Bioscience and Biotechnology, National Taiwan Ocean University, Keelung, 20224, Taiwan

$\uparrow$ Electronic supplementary information (ESI) available: Fig. S1-S8. See DOI: $10.1039 / \mathrm{b} 808594 \mathrm{c}$ trihydrate $\left(\mathrm{HAuCl}_{4} \cdot 3 \mathrm{H}_{2} \mathrm{O}\right)$, we prepared $\mathrm{Au}$ NPs having diameters ranging from 2.2 to $3.7 \mathrm{~nm}$. Introduction of 11-mercaptoundecanoic acid (11-MUA) ligands onto the surfaces of the as-prepared Au NPs resulted in luminescent 11-MUA-Au NDs. The as-prepared spherical 11-MUA-Au NDs of various sizes emitted light at different wavelengths within the range 500-640 $\mathrm{nm}$. Likewise, by controlling the molar ratio of the Au and Ag ions, we prepared 11-MUA-protected $\mathrm{Au} / \mathrm{Ag}$ NDs having similar sizes; these NDs emitted light at different wavelengths within the range $456-525 \mathrm{~nm}$.

\section{Materials and methods}

\section{Chemicals}

Silver nitrate, 11-MUA, sodium borohydride, THPC and trisodium citrate dihydrate were purchased from Aldrich (Milwaukee, WI, USA). Sodium tetraborate and $\mathrm{HAuCl}_{4} \cdot 3 \mathrm{H}_{2} \mathrm{O}$ were obtained from Acros (Geel, Belgium).

\section{Preparation of THPC-Au NPs}

The THPC-Au NPs were synthesized through reduction of $\mathrm{HAuCl}_{4} \cdot 3 \mathrm{H}_{2} \mathrm{O}$ with THPC. A representative procedure is described: $1 \mathrm{M} \mathrm{NaOH}$ (1 mL; Aldrich) was diluted in water $(50 \mathrm{~mL})$ and then THPC solution $(80 \%$ aqueous solution, $24 \mu \mathrm{L})$ was added. The resulting THPC solution $(250 \mu \mathrm{L})$ was reacted for $5 \mathrm{~min}$ and then it was mixed with $\mathrm{HAuCl}_{4} \cdot 3 \mathrm{H}_{2} \mathrm{O}$ solution $(1.2 \mathrm{mM}, 250 \mu \mathrm{L})$. The mixture was subjected to vortexing vigorously at ambient temperature and pressure for $15 \mathrm{~min}$. The average size of the as-prepared THPC-Au NPs $(3.4 \pm 1.0 \mathrm{~nm})$ was determined using a TEM (Tecnai 20 G2 S-Twin TEM, Philips/FEI, Hillsboro, Oregon).

\section{Preparation of $\mathrm{NaBH}_{4}-\mathrm{Au}$ NPs}

The $\mathrm{NaBH}_{4}-\mathrm{Au}$ NPs were synthesized through reduction of $\mathrm{HAuCl}_{4} \cdot 3 \mathrm{H}_{2} \mathrm{O}$ with $\mathrm{NaBH}_{4}$, according to a slight modification of a reported procedure. ${ }^{17}$ An aqueous solution $(20 \mathrm{~mL})$ was 
prepared containing $0.25 \mathrm{mM} \mathrm{HAuCl} 4$ and $0.25 \mathrm{mM}$ trisodium citrate. Next, $0.01 \mathrm{M} \mathrm{NaBH}_{4}$ solution $(0.6 \mathrm{~mL})$ was added in one portion into the $\mathrm{HAuCl}_{4}$ solution under constant stirring. After stirring for another $30 \mathrm{~s}$ the solution turned brown, indicating the formation of the $\mathrm{NaBH}_{4}-\mathrm{Au}$ NPs. The average size $(3.3 \pm 0.4$ $\mathrm{nm}$ ) of the as-prepared $\mathrm{NaBH}_{4}-\mathrm{Au} \mathrm{NPs}$ was determined using a TEM.

\section{Preparation of luminescent 11-MUA-Au NDs}

DI water $(300 \mu \mathrm{L})$, trisodium tetraborate $(50 \mathrm{mM}, \mathrm{pH} 9.2,100$ $\mu \mathrm{L}), 11-\mathrm{MUA}(100 \mathrm{mM}, 100 \mu \mathrm{L})$, and the as-prepared THPC- or $\mathrm{NaBH}_{4}-\mathrm{Au}$ NPs $(500 \mu \mathrm{L})$ were added sequentially to a $1.5 \mathrm{~mL}$ vial. The mixtures were then left to react for $72 \mathrm{~h}$ in the dark at room temperature to form the 11-MUA-Au NDs. We purified the fluorescent 11-MUA-Au NDs by conducting centrifugal filtration $(13,500 \mathrm{~g})$ for $40 \mathrm{~min}$ through a filter having a cutoff of $10 \mathrm{kDa}$. We then washed the pellets with $3.5 \mathrm{~mL}$ of tetraborate. Most of the 11-MUA and precursors in the solution were removed. We then measured the fluorescence of the removed solution, showing a very weak luminescence when excited at 375 $\mathrm{nm}$. The results reveal that the luminescence signal is truly from 11-MUA-Au NDs. The absorption and luminescence spectra of the 11-MUA-Au NDs were recorded using a UV-Vis absorption spectrophotometer (Cintra 10e; GBC, Victoria, Australia) and a luminescence spectrophotometer (Cary Eclipse; Varian, CA, USA), respectively.

\section{Preparation of luminescent 11-MUA-Au/Ag NDs}

First, we prepared THPC-Au/Ag NPs in the presence of $\mathrm{AgNO}_{3}$ at various $\mathrm{Ag}$-to-Au ion molar ratios at a constant total ion concentration $(0.6 \mathrm{mM})$ of $\mathrm{Ag}$ and $\mathrm{Au}$; next, we subjected them to reactions with 11-MUA to prepare 11-MUA-Au/Ag NDs. Energy-dispersive X-ray spectroscopy (EDS) analysis of the 11MUA-Au/Ag NDs using a $0.7 \mathrm{~nm}$ diameter electron probe was employed to determine their chemical identities. The measurements were conducted by illuminating an electron beam on a whole particle. The contents of $\mathrm{Au}^{+}$and $\mathrm{Ag}^{+}$ions were quantitatively determined by inductively coupled plasma mass spectrometry (ICP-MS) measurement.

\section{Results and discussion}

First, we prepared small Au NPs (sizes <4.0 nm) from $\mathrm{HAuCl}_{4}$ by using two common reducing agents, THPC and $\mathrm{NaBH}_{4}$, separately. When using $\mathrm{NaBH}_{4}$, we added citrate (capping agent) to stabilize the as-prepared Au NPs. It is believed that THPC and $\mathrm{NaBH}_{4}$ reduce $\mathrm{Au}^{3+}$ ions through the formation of formaldehyde and hydrogen, respectively. ${ }^{16,17}$ Using transmission electron microscopy (TEM, Fig. 1), we determined (from counts of 100 particles) that the sizes of the spherical Au NPs formed through reduction of $\mathrm{HAuCl}_{4} \cdot 3 \mathrm{H}_{2} \mathrm{O}$ with THPC and $\mathrm{NaBH}_{4}$ were 3.4 $( \pm 1.0)$ and $3.3( \pm 0.4) \mathrm{nm}$, respectively. Herein, we denote the $\mathrm{Au}$ NPs prepared through reduction with THPC and $\mathrm{NaBH}_{4}$ as THPC-Au NPs and $\mathrm{NaBH}_{4}-\mathrm{Au} \mathrm{NPs}$, respectively. After reacting these NPs with 11-MUA (10 mM), which forms very strong covalent, distinctly directional $\mathrm{Au}-\mathrm{S}$ bonds on the $\mathrm{Au}$ NP surfaces, ${ }^{18,19}$ we obtained two sets of 11-MUA-Au NDs having sizes of $1.4( \pm 0.4)$ and $2.8( \pm 0.4) \mathrm{nm}$, respectively (Fig. 1). We
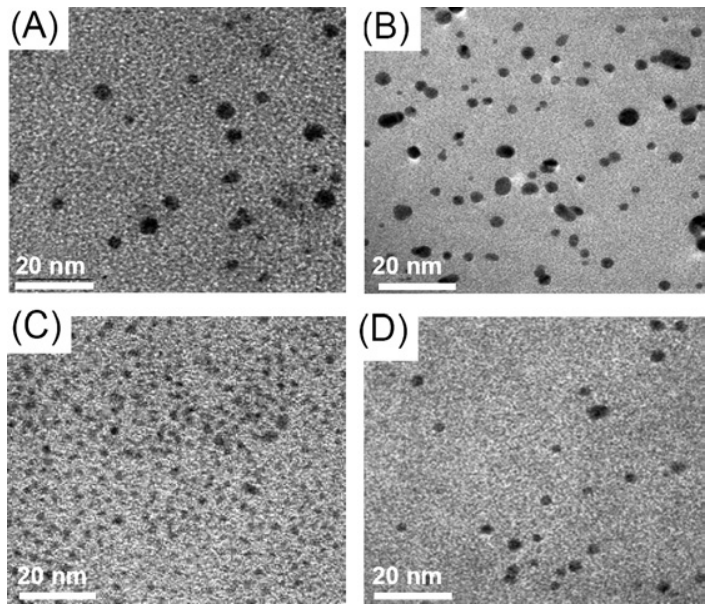

Fig. 1 TEM images of the (A) THPC-Au NPs, (B) $\mathrm{NaBH}_{4}-\mathrm{Au} \mathrm{NPs}$, and (C, D) 11-MUA-Au NDs from (C) THPC-Au NPs and (D) $\mathrm{NaBH}_{4-}$ AuNPs after etching with 11-MUA.

believe that the sizes of these NDs decreased after treatment with 11-MUA because of producing significant fragmentation energies; i.e., once the 11-MUA units adsorbed onto the Au NPs' surfaces, they tended to dissociate into smaller $\mathrm{Au}$ and $\mathrm{Au}-$ thiolate clusters. ${ }^{18,19}$ The decrease in size from the THPC-Au NPs was greater than that from the $\mathrm{NaBH}_{4}-\mathrm{Au} \mathrm{NPs}$, presumably because the citrate stabilization of the latter made it difficult for 11-MUA molecules to access the surface and etch the Au atoms. We suspect that the weak, but distinguishable, SPR absorption at $520 \mathrm{~nm}$ (curve D, Fig. 2a) of the solution is due to existence of some original $\mathrm{NaBH}_{4}-\mathrm{Au}$ NPs. The solution does not exhibit luminescence (Fig. 2b). In contrast, the 11-MUA-Au NDs prepared from the THPC-Au NPs exhibited an absorption band centered at a wavelength $\left(\lambda_{\max }^{\mathrm{abs}}\right)$ of $375 \mathrm{~nm}$ (extinction coefficient:
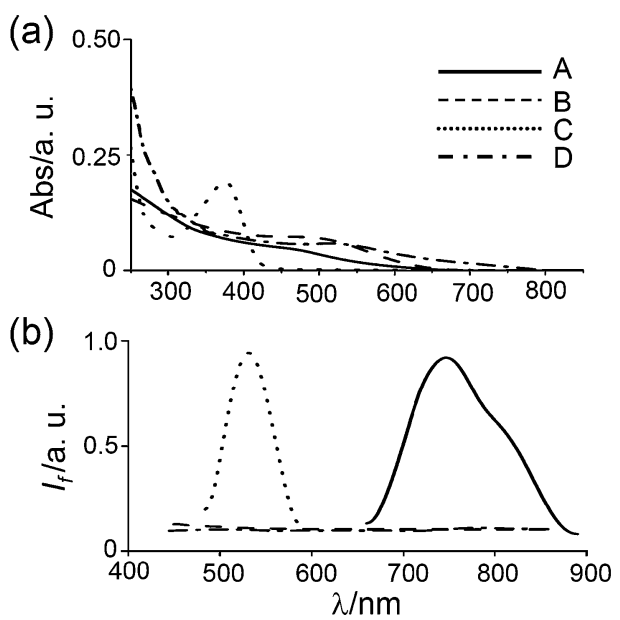

Fig. 2 (a) UV-Vis absorption spectra, (b) and normalized luminescence spectra of solutions of the (A) THPC-Au NPs, (B) $\mathrm{NaBH}_{4}-\mathrm{Au} \mathrm{NPs}$, and (C, D) 11-MUA-Au NDs from (C) THPC-Au NPs and (D) $\mathrm{NaBH}_{4}-\mathrm{Au}$ NPs after etching with 11-MUA. The normalized luminescence intensities $\left(I_{f}\right)$ are plotted in arbitrary units (a. u.); excitation wavelength: $375 \mathrm{~nm}$. In (b), the ratio of concentrations of solutions (A), (B), (C), and (D) was $23,000: 23,000: 1: 23,000$. 
$2.5 \times 10^{6} \mathrm{M}^{-1} \mathrm{~cm}^{-1}$ ) and stronger luminescence at $525 \mathrm{~nm}$ when excited at $375 \mathrm{~nm}$ (Fig. 2).

The absorption bands for 11-MUA-Au NDs are believed to originate from metal-centered $\left(\mathrm{Au} 5 \mathrm{~d}^{10}\right.$ to $6 \mathrm{sp}$ interband transitions) and/or ligand-metal charge transfer transitions. ${ }^{4-11,20-22}$ The luminescence intensity at $525 \mathrm{~nm}$ of these NDs was $c a$. 23,000 -fold higher than that of the THPC-Au NPs at $750 \mathrm{~nm}$. Through comparison with quinine ( $\mathrm{QY}=53 \%)$, the QYs of the THPC-Au NPs and the 11-MUA-Au NDs prepared from them were $0.0001 \%$ and $4 \%$, respectively. We demonstrate the purified 11-MUA-Au NDs sample was stable (no precipitates formed) for at least 3 months when stored at $4{ }^{\circ} \mathrm{C}$ in the dark by light scattering experiments. The intensities of static light scattering of fresh- and stored- 11-MUA-Au NDs (100 nM) were determined to be close $(290 \pm 15 \mathrm{kcps}, \mathrm{n}=5)$ by using a particle size analyzer (Zetasizer Nano, Malvern). In addition, the luminescence intensity of the stored 11-MUA-Au NDs was almost the same as that of the freshly prepared ones (Fig. S1†). The as-prepared 11-MUA-Au NDs from THPC-Au NPs had a Stokes shift of $150 \mathrm{~nm}$ and lifetimes $\left(\mathrm{t}_{1} / \mathrm{t}_{2}\right)$ of $274 / 1134 \mathrm{~ns}$ by fitting to a biexponential luminescence decay (Fig. 3). Large Stokes-shifted luminescence with long lifetimes is a general characteristic of thiol-Au(I) complexes that display ligand-metal charge transfer and metal(I)-metal(I) interactions. ${ }^{20-22}$ Thus, we suspect that our brightly luminescent 11-MUA-Au NDs were $\mathrm{Au} \mathrm{ND} /$ polynuclear $\mathrm{Au}(\mathrm{I})$-thiol (core/shell) complexes.

We obtained differently sized THPC-Au NPs upon varying the THPC-to- $\mathrm{HAuCl}_{4}$ molar ratio, which controlled the seeding and growth rates. First, we prepared THPC-Au NPs by varying this molar ratio over the range 1.0-3.5; then we subjected the as-prepared THPC-Au NPs to reactions with 11-MUA to form 11-MUA-Au NDs. Fig. 4 reveals that this strategy resulted in differently sized 11-MUA-Au NDs that emitted colors ranging from green to reddish (Fig. S2 $†$ ), with corresponding emission wavelengths ranging from 500 to $640 \mathrm{~nm}$. The corresponding TEM images (Fig. S3 $†$ ) indicated that the THPC-Au NPs prepared from $\mathrm{HAuCl}_{4}(0.6 \mathrm{mM})$ at THPC-to- $\mathrm{HAuCl}_{4}$ molar ratios of 1.0, 2.0, and 3.5 were well dispersed and had average diameters of $3.6( \pm 2.1), 2.9( \pm 0.6)$, and $2.2( \pm 0.6) \mathrm{nm}$,

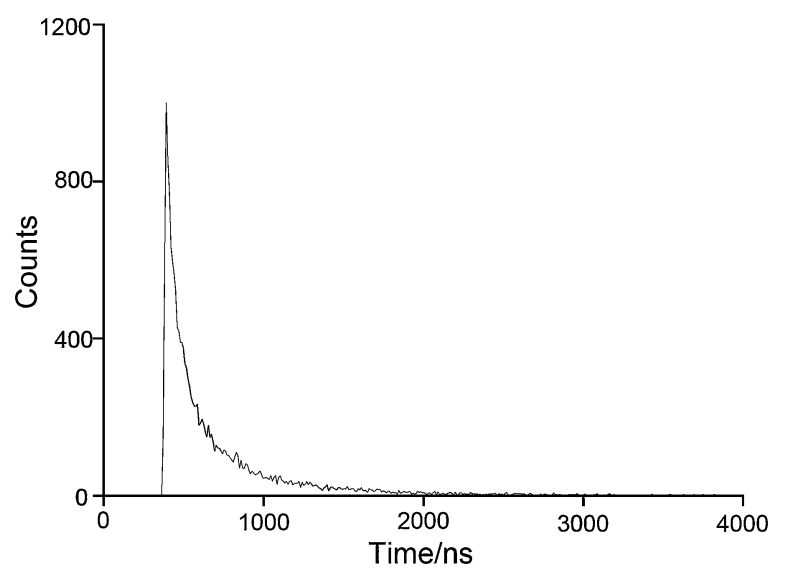

Fig. 3 Luminescence lifetime, after excitation at $375 \mathrm{~nm}$, of the 11MUA-Au NDs prepared from the THPC-Au NPs. The luminescence decay was fitted to a biexponential decay. Other conditions were the same as those described in Fig. 2.

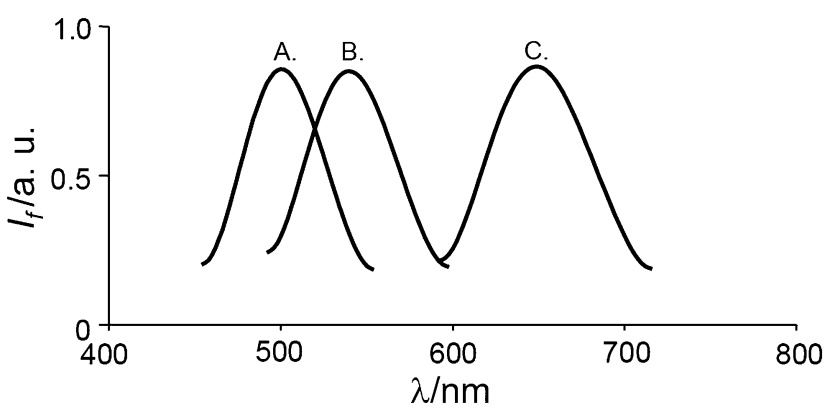

Fig. 4 Normalized luminescence spectra of 11-MUA-Au NDs prepared at THPC-to-HAuCl $\mathrm{H}_{4}$ concentration ratios of (A) 1.0, (B) 2.0, and (C) 3.5. Excitation wavelengths: (A) 400, (B) 370, and (C) $276 \mathrm{~nm}$. The concentration ratio of solutions (A), (B), and (C) was $1.5: 1.0: 151.8$.

respectively. Thus, upon increasing the THPC-to- $\mathrm{HAuCl}_{4}$ molar ratio, the sizes of the THPC-Au NPs decreased, primarily because of the higher seeding rate in the presence of a larger amount of reducing agent. ${ }^{17} \mathrm{Fig} .4$ presents the luminescence spectra of the three 11-MUA-Au ND solutions that we prepared from the three differently sized THPC-Au NPs. Because these three 11-MUA-Au ND solutions possessed different luminescence QYs, their luminescence spectra are presented after normalization.

Table 1 provides a comparison of the sizes and optical properties of the three as-prepared 11-MUA-Au NDs. The size distribution histograms of 11-MUA-Au NDs are displayed in Fig. S4 (see ESI + ). It is interesting that we obtained smaller 11MUA-Au NDs from the larger-sized THPC-Au NPs. We suspect that because the smaller THPC-Au NPs were prepared at greater THPC-to- $\mathrm{HAuCl}_{4}$ molar ratios, the excess of THPC in solution inhibited the 11-MUA molecules from accessing the surface and etching the Au NPs. The larger 11-MUA-Au NDs exhibited emissions at longer wavelengths; e.g., the $1.2( \pm 0.2)$ and $2.1( \pm 0.1)$-nm 11-MUA-Au NDs emitted light at 500 and $640 \mathrm{~nm}$, respectively. Presumably the luminescence wavelength underwent a blue shift upon decreasing the THPC-to-HAuCl${ }_{4}$ molar ratio primarily because of the decreased ND size (Table 1) and increased the contribution of the 11-MUA-passivated surfaces, which decreased the energy gap between the quantized levels as a result of a smaller core and a higher coverage of thiolate. ${ }^{20}$ Our reasoning was supported by the facts of long life times and a large Stokes shift of the 11-MUA-Au NDs. Like quantum dots, the fluorescence of 11-MUA-Au NDs is dependent on many parameters, including the nature and size of the NDs, the surface, and solution composition.

To probe the detailed electronic structure of the 11-MUA-Au NDs, we used X-ray photoelectron spectroscopy (XPS) to

Table 1 Sizes and optical properties of 11-MUA-Au NDs prepared at various ratios of [THPC]-to-[HAuCl 4$]$ ratios

\begin{tabular}{lccccl}
\hline$\left[\mathrm{THPC}^{\prime} /\right.$ & Size $(\mathrm{nm})$ & $\begin{array}{c}\lambda_{\max }^{\mathrm{ex}} \\
(\mathrm{nm})\end{array}$ & $\begin{array}{l}\lambda_{\max }^{\mathrm{em}} \\
(\mathrm{nm})\end{array}$ & $\mathrm{QY}$ & $\begin{array}{l}\text { Binding energy } \\
(\mathrm{eV}) \text { of } \mathrm{Au}\left(4 \mathrm{f}_{7 / 2}\right)\end{array}$ \\
\hline 1.0 & $1.2 \pm 0.2$ & 400 & 500 & $3.8 \%$ & 84.90 \\
2.0 & $1.7 \pm 0.2$ & 370 & 550 & $3.9 \%$ & 84.25 \\
3.5 & $2.1 \pm 0.1$ & 276 & 640 & $0.2 \%$ & 84.05 \\
\hline
\end{tabular}




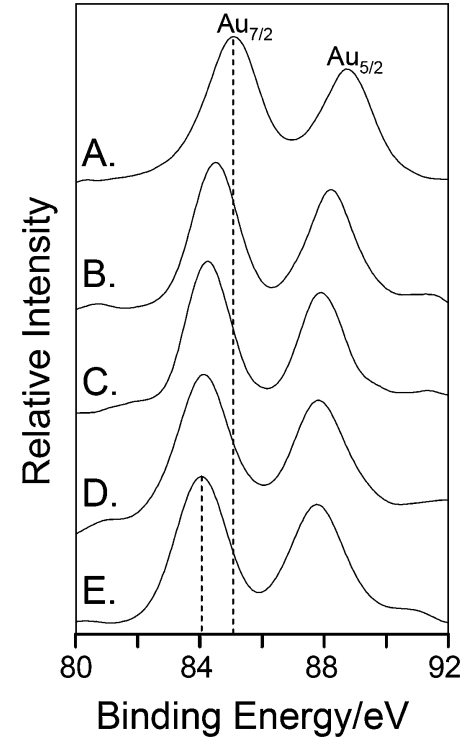

Fig. $5 \mathrm{Au} 4 \mathrm{f}$ core-level photoelectron spectra of (A) the $\mathrm{Au}(\mathrm{I})$ complex, (B-D) the 11-MUA-Au NDs of various sizes, and (E) a Au evaporated film dosed onto silicon substrates and measured at room temperature. The mean diameters of the NDs were (B) 1.2, (C) 1.7, and (D) $2.1 \mathrm{~nm}$.

investigate the oxidation states of their surfaces (Fig. 5). Table 1 lists the binding energies (BE) of the $\mathrm{Au} 4 \mathrm{f}_{7 / 2}$ electrons, a common signature for $\mathrm{Au}$ oxidation states when using the $\mathrm{BE}$ $(285.3 \mathrm{eV})$ of the alkyl chain $\mathrm{C} 1 \mathrm{~s}$ orbital as an internal reference. ${ }^{23}$ The BEs for the $\mathrm{Au} 4 \mathrm{f}_{7 / 2}$ electrons in the 11-MUA-Au NDs fell within the region from $84.02 \mathrm{eV}(\mathrm{Au})$ to $85.00 \mathrm{eV}$ (polynuclear $\mathrm{Au}(\mathrm{I})-11-\mathrm{MUA}$ complex). The smaller 11-MUA$\mathrm{Au}$ NDs exhibited greater shifts to higher $\mathrm{BE}$ for their $\mathrm{Au} 4 \mathrm{f}_{7 / 2}$ electrons, relative to that of bulk $\mathrm{Au}$ crystallites. Upon decreasing the particle diameter, the NDs have a higher ratio of 11-MUA-bonded surface Au atoms relative to atoms in the bulk. The BE shifted to a greater extent for the smaller NDs because of the greater contribution of the 11-MUA-passivated surfaces (i.e., the higher-BE component) to the $\mathrm{Au}_{4 \mathrm{f}}$ core-level photoemission spectrum. ${ }^{24}$

We then investigated the effect of $\mathrm{AgNO}_{3}$ on the preparation of luminescent $\mathrm{Au} / \mathrm{Ag}$ NDs. We suspected that these NPs and NDs were both $\mathrm{Au} / \mathrm{Ag}$ alloys because there we observed no obvious lattice mismatch or core/shell-like structure (Fig. 6). ${ }^{25,26}$ The observed lattice constant $(2.38 \AA)$ corresponds to the $d$ spacing of the (111) crystal plane of an fcc structure. It has been reported that $\mathrm{Au} / \mathrm{Ag} \mathrm{NPs}$ have lattice constants that resemble those of $\mathrm{Ag}$ and $\mathrm{Au}$ NPs. ${ }^{25,26}$ The EDS spectrum of the 11MUA-Au/Ag NDs prepared at an Ag-to-Au molar ratio of 2.0 is shown in Fig. S5 (see ESI $\dagger$ ), indicating the presence of $\mathrm{Ag}$ and $\mathrm{Au}$ in the NDs and also $\mathrm{C}, \mathrm{O}$, and $\mathrm{S}$ from the 11-MUA molecules. The $\mathrm{Cu}$ peaks are due to the copper grid used in the sample preparation. The ratio of $\mathrm{Ag} / \mathrm{Au}$ was determined from $\mathrm{AgL}$ and AuL lines to be 1.52, which agrees with that (1.60) obtained by ICP-MS measurements. Fig. 7 indicates that the as-prepared 11-MUA-Au/Ag NDs had tunable luminescence properties at wavelengths ranging from 456 to $525 \mathrm{~nm}$. From analyses of TEM images, we estimated that the THPC-Au/Ag NPs and 11MUA-Au/Ag NDs had sizes of $2.6( \pm 0.7)$ and $1.7( \pm 0.3) \mathrm{nm}$,
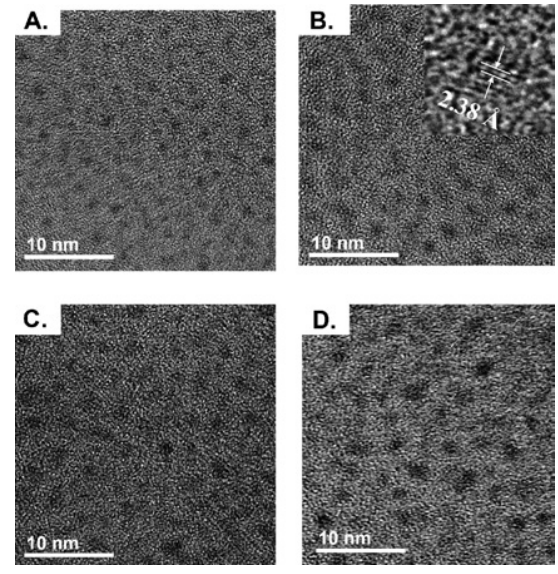

Fig. 6 TEM images of the 11-MUA-Au/Ag NDs prepared at Ag-to-Au ratios of (A) 0 , (B) 0.125 , (C) 0.800 , and (D) 2.000. Inset to (B) is the highresolution TEM image. Other conditions were the same as those described in Fig. 2.

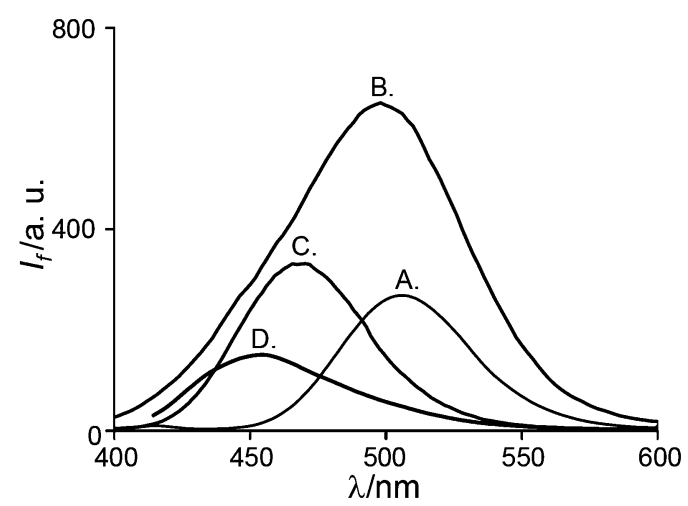

Fig. 7 Luminescence spectra of 11-MUA-Au/Ag NDs prepared at $\mathrm{AgNO}_{3}$-to- $\mathrm{HAuCl}_{4}$ molar ratios of (A) 0, (B) 0.125, (C) 0.800, and (D) 2.000, respectively. Excitation wavelengths: (A) $375 \mathrm{~nm}$; (B)-(D) $330 \mathrm{~nm}$.

respectively (Fig. 6). The size distribution histograms of 11MUA-Au/Ag NDs are displayed in Fig. S6 (see ESI $\dagger$ ). Upon increasing the concentration of $\mathrm{AgNO}_{3}$, the emitted colors of the 11-MUA-Au/Ag NDs range from yellow to blue (Fig. S7 $\dagger$ ), with corresponding emission wavelengths ranging from 525 to 456 $\mathrm{nm}$. It has been suggested that deposition of $\mathrm{Ag}$ atoms onto $\mathrm{Au}$ NPs causes a blue shift in the SPR absorption. ${ }^{27}$ Thus, we suspected that the luminescence properties of these 11-MUA-Au/ $\mathrm{Ag}$ NDs were related to their Au/Ag molar ratios. We confirmed this suspicion by conducting ICP-MS measurements (Table 2). The ICP-MS data reveal that the Ag contents in the 11-MUA$\mathrm{Au} / \mathrm{Ag}$ NDs were higher when the NDs were prepared in solutions containing higher concentrations of $\mathrm{AgNO}_{3}$.

To further investigate the blue-shift of these 11-MUA-Au/Ag NDs upon increasing the $\mathrm{Ag}$ content, we prepared a series of mixtures of 11-MUA (10 mM), $\mathrm{HAuCl}_{4}$, and $\mathrm{AgNO}_{3}$, with $\mathrm{Ag}^{+}$to- $\mathrm{Au}^{3+}$ molar ratios of $0,0.20,0.50,0.67,1.00$, and 1.50 at a constant total ion concentration $(0.3 \mathrm{mM})$ of $\mathrm{Au}^{3+}$ and $\mathrm{Ag}^{+}$. Upon increasing the $\mathrm{Ag}^{+}$concentration, the luminescence at 620 $\mathrm{nm}$ decreased, but that at $445 \mathrm{~nm}$ increased (Fig. S8 $†$ ); note that luminescence at $445 \mathrm{~nm}$ is a characteristic of $\mathrm{Ag}(\mathrm{SR})_{\mathrm{n}}$ clusters. ${ }^{28}$ 
Table 2 Sizes, optical properties, and Ag-to-Au mole ratios of 11MUA-Au/Ag NDs prepared at various $\left[\mathrm{AgNO}_{3}\right]$-to- $\left[\mathrm{HAuCl}_{4}\right]$ ratios

\begin{tabular}{llllll}
\hline$\left[\mathrm{AgNO}_{3}\right] /\left[\mathrm{HAuCl}_{4}\right]$ & $\begin{array}{l}\text { Size } \\
(\mathrm{nm})\end{array}$ & $\begin{array}{l}\lambda_{\max }^{\mathrm{ex}} \\
(\mathrm{nm})\end{array}$ & $\begin{array}{l}\lambda_{\max }^{\mathrm{em}} \\
(\mathrm{nm})\end{array}$ & $\mathrm{QY}$ & $\mathrm{Ag} / \mathrm{Au}^{a}$ \\
\hline 0 & $1.4 \pm 0.2$ & 375 & 525 & $1.9 \%$ & 0 \\
0.125 & $1.7 \pm 0.1$ & 330 & 500 & $3.2 \%$ & 0.12 \\
0.800 & $1.6 \pm 0.2$ & 330 & 478 & $2.3 \%$ & 0.64 \\
2.000 & $1.7 \pm 0.2$ & 330 & 456 & $0.5 \%$ & 1.60 \\
${ }^{a}$ Calculated from the ICP-MS data. \\
\hline
\end{tabular}

It has been reported that organic-soluble tiopronin-coated $\mathrm{Ag}$ clusters $(1.6 \mathrm{~nm})$ react with $\mathrm{Au}(\mathrm{I})\left[\mathrm{SCH}_{2}\left(\mathrm{C}_{6} \mathrm{H}_{4}\right) \mathrm{C}\left(\mathrm{CH}_{3}\right)_{3}\right]$ to form $\mathrm{Ag} / \mathrm{Au}$ bimetallic cores, with a concomitant red-shift of the luminescence. ${ }^{29}$ The behavior of our 11-MUA-Au/Ag NDs is consistent with those findings; i.e., the blue shift in the as-prepared 11-MUA-Au/Ag NDs was due primarily to an increased $\mathrm{Ag}$ content.

\section{Conclusions}

We have demonstrated that controlling the THPC-to- $\mathrm{HAuCl}_{4}$ molar ratio allows tuning of the luminescence wavelength of 11-MUA-Au NDs. We have also demonstrated the preparation of 11-MUA-Au/Ag NDs that emit luminescence at tunable wavelengths within the region from 456 to $525 \mathrm{~nm}$. Our prepared 11-MUA-Au NDs and 11-MUA-Au/Ag NDs exhibit a number of attractive optical properties: tunable luminescence wavelengths, long lifetimes (>250 ns), and large Stokes shifts $(>100 \mathrm{~nm})$. These properties suggest that the as-prepared 11MUA-Au NDs and 11-MUA-Au/Ag NDs would be suitable for use in sensing applications after bio-conjugation. ${ }^{30-34}$ Much like semiconductor quantum dots (QDs), the highly size- and surface-dependent luminescence properties of these NDs are also very sensitive to the environment. ${ }^{34-36}$ Unlike semiconductor QDs, however, the QYs of luminescent Au NDs are lower. Nevertheless, these luminescent NDs are easy to prepare, exhibit good batch-to-batch reproducibility (relative standard deviation: $<5 \%$ from 10 batches) in terms of their luminescence intensity, and have low toxicity. ${ }^{37-40}$ Although the QYs of our thus-prepared luminescent $\mathrm{Au}$ NDs are lower than those of dendrimer-protected $\mathrm{Au}$ clusters $\left(\mathrm{ca} . \mathrm{Au}_{40}\right),{ }^{20}$ the 11-MUA-Au NDs $\left(c a . \mathrm{Au}_{250}\right)$ and 11-MUA-Au/Ag NDs are readily purified and/or separated from the other matrix components through simple centrifugal filtration (membrane cutoff: $10 \mathrm{kDa}$ ). Indeed, we have successfully applied functionalized fluorescent Au NDs for sensing proteins in biological samples and mercury ion in environmental samples. ${ }^{15,40}$

\section{Acknowledgements}

We are grateful to the National Science Council of Taiwan for providing financial support to this study under contracts NSC
95-2113-M-002-026-MY3, NSC 97-2627-M-002-010, and NSC 97-2627-M-002-011.

\section{References}

1 G. Hodes, Adv. Mater., 2007, 19, 639.

2 S. Link and M. A. El-Sayed, Annu. Rev. Phys. Chem., 2003, 54, 331.

3 C. Li, K. L. Shuford, M. Chen, E. J. Lee and S. O. Cho, ACS Nano, 2008, 2, 1760.

4 T. Huang and R. W. Murray, J. Phys. Chem. B, 2001, 105, 12498.

5 G. Wang, T. Huang, R. W. Murray, L. Menard and R. G. Nuzzo, J. Am. Chem. Soc., 2005, 127, 812.

6 S. Link, A. Beeby, S. FitzGerald, M. A. El-Sayed, T. G. Schaaff and R. L. Whetten, J. Phys. Chem. B, 2002, 106, 3410.

7 G. Wang, R. Guo, G. Kalyuzhny, J.-P. Choi and R. W. Murray, J. Phys. Chem. B, 2006, 110, 20282.

8 Y. Negishi and T. Tsukuda, Chem. Phys. Lett., 2004, 383, 161

9 Y. Negishi, K. Nobusada and T. Tsukuda, J. Am. Chem. Soc., 2005, 127, 5261 .

10 Y. Yang and S. Chen, Nano Lett., 2003, 3, 75.

11 S. Link, M. A. El-Sayed, T. G. Schaaff and R. L. Whetten, Chem. Phys. Lett., 2002, 356, 240.

12 H. Chander, Mater. Sci. Eng., R, 2005, 49, 113.

13 J. Zheng, C. Zhang and R. M. Dickson, Phys. Rev. Lett., 2004, 93, 077402 .

14 H. Duan and S. Nie, J. Am. Chem. Soc., 2007, 129, 2412.

15 C.-C. Huang, Z. Yang, K.-H. Lee and H.-T. Chang, Angew. Chem., Int. Ed., 2007, 46, 6824.

16 D. G. Duff, A. Baiker and P. P. Edwards, Langmuir, 1993, 9, 2301.

17 N. R. Jana, L. Gearheart and C. J. Murphy, Langmuir, 2001, 17, 6782.

18 D. Krüger, H. Fuchs, R. Rousseau, D. Marx and M. Parrinello, J. Chem. Phys., 2001, 115, 4776.

19 M. Konôpka, R. Rousseau, I. Štich and D. Marx, J. Am. Chem. Soc., 2004, 126, 12103.

20 J. Zheng, P. R. Nicovich and R. M. Dickson, Annu. Rev. Phys. Chem., 2007, 58, 409.

21 J. M. Forward, D. Bohmann, J. P. Fackler and R. J. Staples, Inorg. Chem., 1995, 34, 6330.

22 A. Vogler and H. Kunkely, Coord. Chem. Rev., 2001, 219-221, 489.

23 A. McNeillie, D. H. Brown, W. E. Smith, M. Gibson and L. Watson, J. Chem. Soc., Dalton Trans., 1980, 767.

24 A. Tanaka, Y. Takeda, T. Nagasawa and K. Takahashi, Solid State Commun., 2003, 126, 191.

25 D.-H. Chen and C.-J. Chen, J. Mater. Chem., 2002, 12, 1557.

26 Q. Zhang, J. Y. Lee, J. Yang, C. Boothroyd and J. Zhang, Nanotechnology, 2007, 18, 245605.

27 L. M. Liz-Marzán, Langmuir, 2006, 22, 32.

28 A. Ledo, F. Martínez, M. A. López-Quintela and J. Rivas, Physica B, 2007, 398, 273.

29 T. Huang and R. W. Murray, J. Phys. Chem. B, 2003, 107, 7434.

30 M. Seydack, Biosens. Bioelectron., 2005, 20, 2454.

31 R. R. Arvizo, A. Verma and V. M. Rotello, Supramol. Chem., 2005, $17,155$.

32 U. Drechsler, B. Erdogan and V. M. Rotello, Chem. Eur. J., 2004, 10, 5570.

33 A. C. Templeton, W. P. Wuelfing and R. W. Murray, Acc. Chem. Res., 2000, 33, 27.

34 S. S. Narayanan and S. K. Pal, J. Phys. Chem. C, 2008, 112, 4874.

35 A. P. Alivisatos, W. Gu and C. Larabell, Annu. Rev. Biomed. Eng., 2005, 7, 55.

36 R. E. Bailey, A. M. Smith and S. Nie, Physica E, 2004, 25, 1.

37 R. Hardman, Environ. Health Perspect., 2006, 114, 165.

38 E. E. Connor, J. Mwamuka, A. Gole, C. J. Murphy and M. D. Wyatt, Small, 2005, 1, 325.

39 C. I. Richards, S. Choi, J.-C. Hsiang, Y. Antoku, T. Vosch, A. Bongiorno, Y.-L. Tzeng and R. M. Dickson, J. Am. Chem. Soc., 2008, 130, 5038.

40 C.-C. Huang, C.-K. Chiang, Z.-H. Lin, K.-H. Lee and H.-T. Chang, Anal. Chem., 2008, 80, 1497. 